\title{
SCREENING OF FILAMENTOUS FUNGI FOR PRODUCTION OF XYLITOL FROM D-XYLOSE
}

\author{
Fábio Coelho Sampaio; Wendel Batista da Silveira; Virgínia Maria Chaves-Alves; Flávia Maria Lopes Passos; \\ Jorge Luiz Cavalcante Coelho*
}

Departamento de Microbiologia, Núcleo de Biotecnologia Aplicada à Agropecuária, Universidade Federal de Viçosa, Viçosa, MG, Brasil.

Submitted: November 13, 2002; Returned to Authors for corrections: March 03, 2003; Approved: September 28, 2003

\section{SHORT COMMUNICATION}

\begin{abstract}
Eleven filamentous fungi were screened for xylitol production in batch cultures. Production was generally low under the growth conditions used in this study. Penicillium crustosum presented the highest production, $0.52 \mathrm{~g} \mathrm{~L}^{-1}$ from $11.50 \mathrm{~g} \mathrm{~L}^{-1}$ of D-xylose, representing consumption of $76 \%$ of the original D-xylose.
\end{abstract}

Key words: xylose, bioconversion, xylitol, filamentous fungi.

Xylitol, a five carbon alcohol sugar, is a high value product, due principally to its high sweetening power, non-cariogenic properties and insulin-independent metabolism $(7,8,11,15)$, properties that justify the growing interest in optimizing its production at low cost.

Xylitol is widely distributed in nature, but is found in low concentration in plants and fruits, making its extraction from natural sources economically unfeasible $(7,8,11)$.

Industrial xylitol production is based on chemical reduction of D-xylose, involving acid hydrolysis of xylan-rich lignocellulosic raw material and catalytic hydrogenation of the D-xylose produced to xylitol. Conversion yield is relatively low (50 to 60\%) and product purification requires various unit operations, such as ion exchange, discoloration, and chromatographic separation, which increase commercialization costs and consequently decrease the consumer market (8).

Microbial xylitol production is an alternative to the chemical process. Advantages of the microbial process are that it is performed at mild temperature and pressure conditions, and consequently has lower energy requirements, the bioconversion is highly specific, resulting in higher yields and lower product separation and purification costs as well as cleaner effluents (1).
Selection of microorganisms that ferment $\mathrm{D}$-xylose to xylitol is the first step in developing a bioconversion process. Filamentous fungi, yeast and some bacteria are able to perform this conversion through the action of the $\mathrm{NAD}(\mathrm{P}) \mathrm{H}$-dependent enzyme xylose reductase (XR) (EC 1.1.1.21) $(4,6)$. However, most studies have involved yeast, with special emphasis on the genus Candida $(5,9,10,12,13,14)$.

The study of filamentous fungi capable of performing bioconversion of D-xylose to xylitol is justified considering the high pentose concentrations in lignocellulosic residues that are widely distributed in nature, in which xylose is the second most abundant sugar, after glucose. Fungi play an important role in decomposition of this organic matter through enzymatic depolymerization of the plant cell wall (4), and subsequent consumption of the degradation products, among them D-xylose.

The great interest in filamentous fungi stems from their production of enzymes, such as the xylanolytic complex, that is capable of converting xylan-rich lignocellulosic residues to Dxylose, with subsequent xylitol production by bioconversion performed by the same fungi.

Xylitol production by filamentous fungi was first described by Chiang and Knight (4), who worked with Penicillium chrysogenum. In a more recent study, Dahiya (6) observed that

*Corresponding author: Mailing Address. Departamento de Microbiologia, Núcleo de Biotecnologia Aplicada à Agropecuária, Universidade Federal de Viçosa. Av. PH Rolfs s/n. Campus Universitário. 36570-000, Viçosa, MG, Brasil. Tel.: (+5531) 3899-2958. Fax: (+5531) 3899-2573. E-mail: phabcoelho@bol.com.br 
Petromyces albertensis produced $39.8 \mathrm{~g} \mathrm{~L}^{-1} \mathrm{xylitol}$, when grown for 10 days in $100 \mathrm{~g} \mathrm{~L}^{-1}$ xylose. No further studies have been published on the use of filamentous fungi for bioconversion of D-xylose to xylitol.

Considering these facts, we screened several filamentous fungi for capability of converting D-xylose to xylitol and report the results of this screening here.

The following filamentous fungi from the fungal collection of the Microbiology Department of the Federal University of Viçosa (Viçosa, Minas Gerais, Brazil) were used: Penicillium roqueforti CCT 0062, Penicillium crustosum CCT 4034, Penicillium brevicompactum CCT 4457, Penicillium chrysogenum CCT 1273, Penicillium purpurogenum CCT 2008, Penicillium citrinum CCT 3281, Penicillium janthinellum CCT 3162 and Penicillium griseoroseum CCT 6421, deposited at Fundação André Tosello (Campinas, São Paulo, Brazil) and Penicillium expansum VIC, Penicillium italicum DMB1 and Aspergillus niger DMB2, isolated at the University of Viçosa, Viçosa, Brazil. The filamentous fungi were activated in oat-agar medium slants ( $40 \mathrm{~g} \mathrm{~L}^{-1}$ oat flour and $15 \mathrm{~g} \mathrm{~L}^{-1}$ agar) and incubated at $25^{\circ} \mathrm{C}$ until sporulation. The spore-containing slants were maintained at $4^{\circ} \mathrm{C}$. Fresh spore inoculum for screening was produced from the stored cultures using the same conditions. Mineral medium containing $0.62 \mathrm{~g} \mathrm{~L}^{-1} \mathrm{KH}_{2} \mathrm{PO}_{4}, 2.0 \mathrm{~g} \mathrm{~L}^{-1} \mathrm{~K}_{2} \mathrm{HPO}_{4}$, $1.0 \mathrm{~g} \mathrm{~L}^{-1}\left(\mathrm{NH}_{4}\right)_{2} \mathrm{SO}_{4}$ and $1.1 \mathrm{~g} \mathrm{~L}^{-1} \mathrm{MgSO}_{4}$, $\mathrm{pH}$ 6.0, supplemented with $10.0 \mathrm{~g} \mathrm{~L}^{-1} \mathrm{D}$-xylose and $5.0 \mathrm{~g} \mathrm{~L}^{-1}$ yeast extract was used for the screening studies. D-xylose, yeast extract and the $\mathrm{MgSO}_{4}$ solutions were sterilized separately. $10 \mathrm{~mL}$ of growth medium were added to $50 \mathrm{~mL}$ Erlenmeyer flasks, inoculated with $10^{6}$ spores $\mathrm{mL}^{-1}$ and incubated at $30^{\circ} \mathrm{C}$ with rotary shaking of 100 $\mathrm{rpm}$. Aliquots of medium were withdrawn after $0,24,48,72$ and $96 \mathrm{~h}$ of growth and centrifuged at $8,000 \mathrm{~g}$. The supernatant was used for determination of D-xylose and xylitol concentrations by liquid chromatography (HPLC) using a Hewlett Packard series 1050 liquid chromatograph, equipped with a refractive index detector (HP 1047A), and a BIO-RAD Aminex HPX-87H (300 x $7.8 \mathrm{~mm}$ ) column. Chromatographic

conditions were: $0.01 \mathrm{~N} \mathrm{H}_{2} \mathrm{SO}_{4}$ as mobile phase, at a flow rate of $0.7 \mathrm{~mL} \mathrm{~min}^{-1}$, temperature of $60^{\circ} \mathrm{C}$ and injection volume of $20 \mu \mathrm{L}$. Samples were diluted when necessary prior to injection. Growth was estimated by direct measurement of dry mycelial matter $\left(\mathrm{g} \mathrm{L}^{-1}\right)$, after $96 \mathrm{~h}$ of cultivation (3). All screening experiments were performed in duplicate, and results reported represent averages of the experimental values.

In the present study, $P$. chrysogenum, $P$. citriinum, $P$. expansum, $P$. griseoroseum, $P$. italicum, $P$. janthinellum and $P$. purpurogenum consumed all sugar $\left(11.50 \mathrm{~g} \mathrm{~L}^{-1}\right)$ present within the $96 \mathrm{~h}$ growth period, with P. griseoroseum and P. janthinellum deserving special mention for consuming more than half the Dxylose within $48 \mathrm{~h}$ of growth (Fig. 1). On the other hand, A. niger, $P$. brevicompactum, $P$. crustosum and $P$. roqueforti did not consume all the available D-xylose within $96 \mathrm{~h}$.
Table 1. Results of screening of filamentous fungi for xylitol production.

\begin{tabular}{lcccc}
\hline \multicolumn{1}{c}{ Fungus } & $\begin{array}{c}\text { Xylitol } \\
\left(\mathrm{g} \mathrm{L}^{-1}\right)\end{array}$ & $\begin{array}{c}\text { Xylose } \\
\text { Consumption } \\
(\%)\end{array}$ & $\begin{array}{c}\text { Time } \\
(\mathrm{h})^{*}\end{array}$ & $\begin{array}{c}\text { Dry } \\
\text { weight } \\
\left(\mathrm{g} \mathrm{L}^{-1}\right)^{* *}\end{array}$ \\
\hline A. niger & 0.36 & 79 & 96 & 7.20 \\
P. brevicompactum & 0.23 & 20 & 96 & 0.74 \\
P. chrysogenum & 0.22 & 25 & 48 & 6.92 \\
P. citrinum & 0.27 & 52 & 72 & 5.19 \\
P. crustosum & 0.52 & 76 & 96 & 8.16 \\
P. expansum & 0.15 & 52 & 48 & 5.12 \\
P. griseoroseum & 0.16 & 75 & 24 & 4.38 \\
P. italicum & 0.16 & 15 & 48 & 5.42 \\
P. janthinellum & 0.29 & 72 & 48 & 7.15 \\
P. purpurogenum & 0.14 & 18 & 48 & 5.44 \\
P. roqueforti & 0.27 & 16 & 96 & 0.66 \\
\hline
\end{tabular}

* Time of maximum xylitol production

** Mycelial mass after $96 \mathrm{~h}$ of growth.

Maximum xylitol production varied from 0.14 to $0.52 \mathrm{~g} \mathrm{~L}^{-1}$ (with an initial D-xylose concentration of $11.50 \mathrm{~g} \mathrm{~L}^{-1}$ ), with substrate consumption between 15 and 79\% (Table 1), while volumetric productivity varied from 0.002 to $0.006 \mathrm{~g} \mathrm{~L}^{-1} \mathrm{~h}^{-1}$ (data not shown). P. crustosum produced the highest xylitol concentration, and produced the highest mycelial mass $(8.16 \mathrm{~g}$ $\left.\mathrm{L}^{-1}\right)$ with $76 \% \mathrm{D}$-xylose consumption $\left(0.52 \mathrm{~g} \mathrm{~L}^{-1}\right)$ within $96 \mathrm{~h}$.

For all the filamentous fungi evaluated, the highest xylitol concentrations were obtained without total D-xylose consumption (Table 1). That is, highest xylitol production and highest fermentation parameter values did not coincide with total D-xylose consumption, indicating some loss of substrate, one of the biggest challenges faced in D-xylose to xylitol bioconversion processes.

A microorganism that produced high xylitol concentrations in a relatively short time would be most interesting for process optimization on an industrial scale, since such an organism would have lower energy requirements and would suffer lower risk of contamination. Some of the filamentous fungi tested produced maximum xylitol concentrations within 24 to $48 \mathrm{~h}$, however this production was relatively low (Table 1 ). For others (A. niger, P. brevicompactum, P. crustosum and P. roqueforti) a longer growth period would be necessary for total D-xylose consumption, since with these species maximum observed xylitol production occurred at $96 \mathrm{~h}$.

Bioconversion by filamentous fungi evaluated in this study does not compare favorably with that performed by yeast, as reported in the literature. Among the various studies reported, two yeast, Candida tropicalis 1004 and Candida guilliermondii FTI-20037, produced 16 to $17 \mathrm{~g} \mathrm{~L}^{-1}$ xylitol from $30 \mathrm{~g} \mathrm{~L}^{-1} \mathrm{D}$-xylose, with all substrate consumed within $48 \mathrm{~h}$. This remarkable production was one of the first reports of relatively 

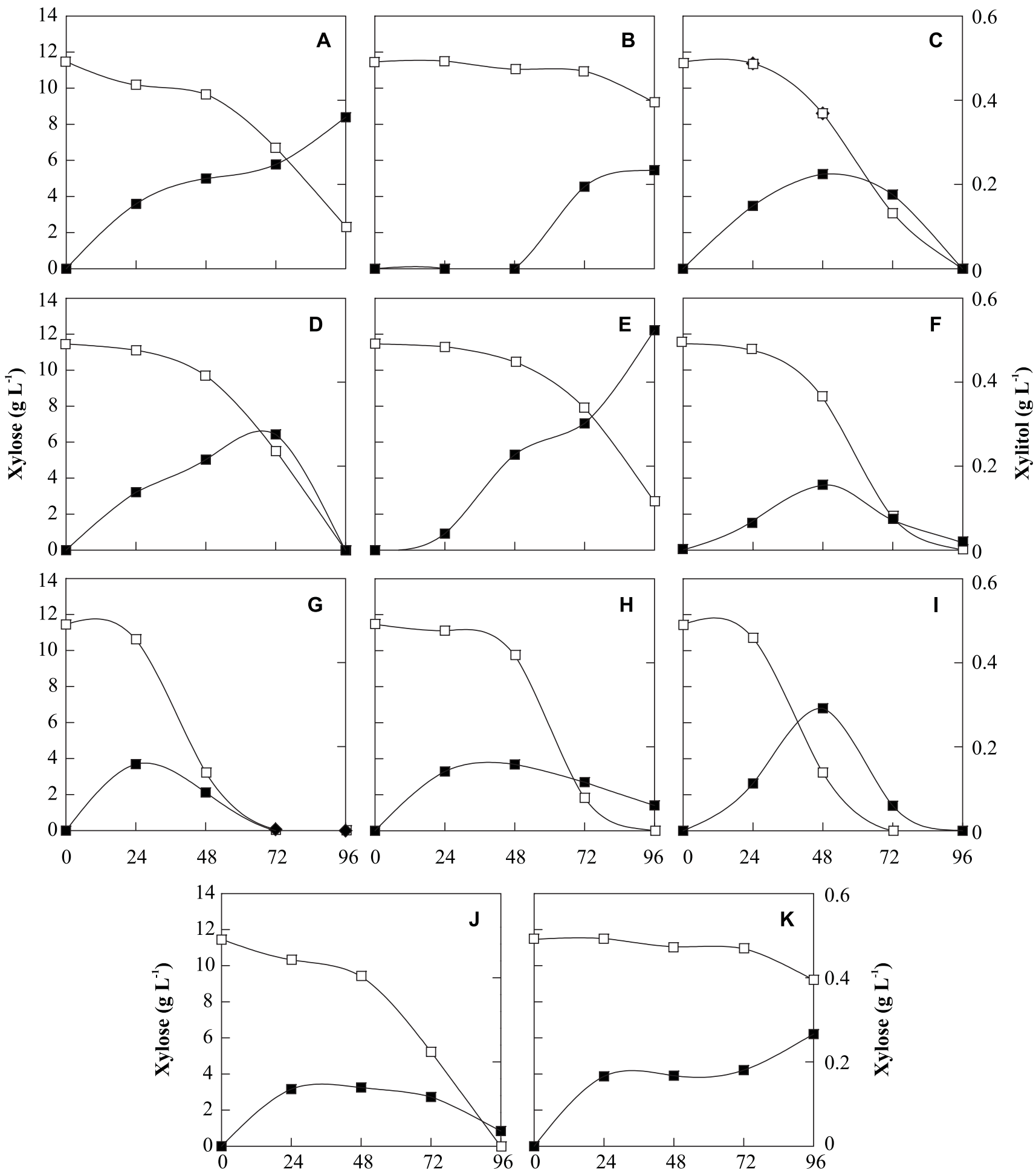

Time (h)

Figure 1. D-xylose consumption ( $\square$ ) and xylitol production ( $\square$ ) by A. niger (A), P. brevicompactum (B), P. chrysogenum (C), $P$. citrinum (D), P. crustosum (E), P. expansum (F), P. griseoroseum $(\mathrm{G})$, P. italicum $(\mathrm{H})$, P. janthnellum $(\mathrm{I})$, P. purpurogenum $(\mathrm{J})$ and $P$. roqueforti $(\mathrm{K})$ grown in batch cultures using mineral medium supplemented with $10 \mathrm{~g} \mathrm{~L}^{-1} \mathrm{D}$-xylose and $5 \mathrm{~g} \mathrm{~L}^{-1}$ yeast extract for 96 h at $\mathrm{pH} 6.0,100 \mathrm{rpm}$ and $30^{\circ} \mathrm{C}$. 
high-yield microbial bioconversion of D-xylose to xylitol in a short incubation period (2).

A possible explanation for the lower xylitol production in filamentous fungi than in yeast is the preeminence of aerobic metabolism in the former. Even under low oxygenation rates, aerobic respiration is more efficient than fermentation, and it can be supposed that D-xylose will be used more efficiently as carbon and energy source, with considerable xylitol dehydrogenase activity due to efficient recovery of $\mathrm{NAD}(\mathrm{P})^{+}$and, consequently, xylitol produced under aerobic conditions will more likely be converted to D-xylulose, and subsequently, to D-xylulose 5phosphate, an intermediate of the pentose pathway.

Considering the importance of these fungi in recycling of xylan-rich lignocellulosic agroindustrial residues, and the possibility of isolating microbial species that convert these to xylitol, further studies are warranted. These should focus on optimization of growth conditions such as D-xylose concentration and oxygenation rates, among others, since the accumulation of xylitol is influenced by numerous factors which must be understood to increase productivity and yield. Furthermore, studies using metabolic engineering considering, for example, cytoplasmatic redox potential under different growth conditions, may contribute to optimization of bioconversion and to an understanding of the interactions among the fungal metabolic pathways involved in D-xylose metabolism.

\section{ACKNOWLEDGEMENTS}

The authors wish to thank the Brazilian agencies Capes, $\mathrm{CNPq}$ and FAPEMIG for financial support.

\section{RESUMO}

\section{Triagem de fungos filamentosos para produção de xilitol a partir de D-xilose}

Foram avaliados onze fungos filamentosos para a produção de xilitol em batelada. A produção foi baixa nas condições de cultivo utilizadas. A máxima, $0,52 \mathrm{~g} \mathrm{~L}^{-1}$ de xilitol a partir de $11,50 \mathrm{~g} \mathrm{~L}^{-1}$ de xilose, foi obtida com Penicillium crustosum, com consumo de $76 \%$ da xilose inicial.

Palavras-chave: Xilose, bioconversão, xilitol, fungos filamentosos.

\section{REFERENCES}

1. Aguiar, W.B.; Andrade, C.M.M.C.; Antunes, J.G.; Araújo, O.Q.F.; Brito, F.H.X.; Damaco, M.C.T.; Faria, L.F.; Fonseca, M.C.C.; Gimenes, M.A.P.; Guerrante, M.F.; Leal, M.L.M.; Lemos, J.L.S.; Motta; R.P.A.; Nóbrega, R.; Sá, M.C.A; Silva, M.L.A.; Pereira, N. Biotecnologia de hemicelulose. $4^{\circ}$ Seminário Brasileiro de Tecnologia Enzimática, ENZITEC, Rio de Janeiro, 1999, p.7176.

2. Barbosa, M.F.S.; Medeiros, M.B.; Mancilha, I.M.; Schneider, H.; Lee, H. Screening of yeasts for production of xylitol from D-xylose and some factors which affect xylitol yield in Candida guilliermondii. J. Ind. Microbiol., 3:241-251, 1988.

3. Calam, C.T. The evaluation of mycelial growth. In: Norris, J.R.; Ribbons, D.W. (Eds.). Methods in Microbiology. Academic Press, London 1969, p.567-591.

4. Chiang, C.; Knight, S.G. Metabolism of D-xylose by moulds. Nature, 188:79-81, 1960.

5. Choi, J.H.; Moon, K.H.; Ryu, Y.W.; Seo, J.H. Production of xylitol in cell recycle fermentations of Candida tropicalis. Biotechnol. Lett., 22:1625-1628, 2000.

6. Dahija, J.S. Xylitol production by Petromyces albertensis grown on medium containing D-xylose. Can. J. Microbiol., 37:14-18, 1991.

7. Emodi, A. Xylitol: Its properties and food applications. Food Technol., 32:28-32, 1978.

8. Hyvönem, L.; Koivistoinen, P.; Voirol, F. Food technological evaluation of xylitol. Adv. Food Res., 28:373-403, 1982.

9. Ikeuchi, T.; Azuma, M.; Kato, J.; Ooshima, H. Screening of microorganisms for xylitol production and fermentation behavior in high concentrations of xylose. Biomass Bioenergy, 16:333-339, 1999.

10. Kern, M.; Haltrich, D.; Nidetzky, B.; Kulbe, K.D. Induction of aldose reductase and xylitol dehydrogenase activities in Candida tenuis CBS 4435. FEMS Microbiol. Lett., 149:31-37, 1997.

11. Mäkinen, K.K. Xylitol and oral health. Adv. Food Res., 25:137$180,1979$.

12. Oh, D-K.; Kim, S-Y.; Kim, J-H. Increase of xylitol production rate by controlling redox potential in Candida parapsilosis. Biotechnol. Bioeng., 58(4):440-444, 1998.

13. Sánchez, S.; Bravo, V.; Castro, E.; Moya, A.J.; Camacho, F. The influence of $\mathrm{pH}$ and aeration rate on the fermentation of D-xylose by Candida shehatae. Enzyme Microb. Technol., 21:355-360, 1997.

14. Sirisansaneeyakul, S.; Staniszewski, M.; Rizzi, M. Screening of yeasts for production of xylitol from D-xylose. J. Ferment. Bioeng., 80(6):565-570, 1995.

15. Yilikari, R. Metabolic and nutritional aspects of xylitol. Adv. Food Res., 25:159-180, 1979 . 